\title{
Development of women's human capital and its impact on economic growth and total factor productivity: A case study of selected OECD countries
}

\author{
Hajar Mostafaee*, Seyed Komail Tayebi and Zahra Zamani
}

Department of Economics, University of Isfahan, Isfahan, 81746, Iran

C H R O I C LE $\quad$ AB S T RAC T

Article history:

Received February 15, 2013

Received in revised format

3 May 2013

Accepted May 42013

Available online

May 62013

Keywords:

Human capital

Growth

Productivity

\begin{abstract}
Experiences of developed countries and various studies in the context of economic growth of developing countries have shown that economic growth is not only explained by physical capital and labor force but also, and more importantly, by human capital. The later variable should be entered, as a major determinant, in the endogenous growth model. With the concern of important role of human capital in this research, the primary objective of this paper is to explore the effect of gender discrimination of human capital on economic growth and factor productivity in Iran and the selected OECD countries. More specifically, to indicate the economic capability of educated females, we use data of the considered countries over the period 1974-2008, to estimate the relevant models of growth and productivity. The implication is to compare the empirical results obtained for Iran and the selected developed countries.
\end{abstract}

\section{Introduction}

Economists mostly believe that the main reason for having slow growth on economy of developing countries is that there has been insufficient investment on human capital. Many countries use science and education to increase their knowledge and professional skills, however, productivity and efficiency of labor and capital levels remain low and economic growth is slow and with greater cost. The only physical capital, where we have sufficient level in some developing countries is the access to sufficient numbers of human capital. Therefore, in a more general explanation of human capital, human capital can be categorized based on their genders. Nowadays, human societies have recognized the role of women in economic development and international institutions like the World Bank (Pritchett, 2001) has considered "gender equality as an economic intelligence”. Recently, there is an increase trend on promoting the participation rate of women in developing countries. There is no doubt that women are accounted as half of the world's population they play essential role on economic growth. Therefore, this study investigates the effect of human capital on growth in Iran and

*Corresponding author. Tel: +98-311-793-2642

E-mail addresses: hajar.mostafaee@gmail.com (H. Mostafaee) 
9 selected OECD countries. This paper is organized in five sections. Section 2 reviews the relevant theoretical literature while section 3 is inspired by the related literature. Section 4 uses time series data and panel data model for estimation, the empirical relationship between economic growth, economic openness and human capital of women and men are examined in this section. Finally, section 5 is devoted to conclusion and offering deals to Iran and selected countries.

\section{Literature review}

The importance of human capital as a source of economic development has long been an economic issue. Adam Smith (1776) is the first classical economist's expertise who explained the difference between intake and efficiency. However, he had some obligation to consider the differences in the labor theory of division of labor in the Wealth of Nations. Adam Smith's division of labor experience and skills, less time consuming and producing machinery was invented. According to the science of training and expertise make the accumulation of human capital, higher productivity and improved technology. Human capital used to be stated as offered education as an investment in human. Then after conventional growth models failed to explain all aspects of economic development, some other economists considered the role of human capital (Abramovitz, 1986). The theoretical studies of Romer (1986) and Lucas (1988), Solow were growth models with various approaches. The first economist Alfred Marshall attempted to quantify the impacts of human capital to estimate the revenue derived from investment in education. Theodore Schultz, who has been called the father of the theory of human capital, has great emphasis on attention to the importance of human capital in economic analysis and believes that regardless of such a theory can explain economic growth and personal income distribution is incomplete. In addition to physical capital and labor, he inserted educational capital stock in the economy and in addition, two other factors, such as improving the quality of human resources, the technology and economies of scale have major contribution to economic growth.

Islam (1995), Lau et al. (1991) indicated the meaning of education and in some cases, negative effects on economic growth. Di Liberto (2008) considered the relationship between growth and human capital in the regions of Italy and used averaged primary education, secondary and high schools and concluded that education plays essential role in development of the South. By analyzing the three main educations, they explained the relative importance of primary education in South, while teaching at the high school level had a negative effect on regional growth. Larson and Morris (2008) examined the impact of gender on the law and concluded that gender had a significant effect on wages and male managers compared with their fellow women in the corporate ranks to higher salaries.

In addition, the foreign trade channel is for the transmission of ideas, thoughts, knowledge and advanced technology. Admission and social adaptation of these technologies strongly rely on human capital in the recipient country (Psacharopoulos, 1972). Human capital can be considered as a main factor on economic growth, which facilitates the adoption of technology across borders. Whenever country in terms of human capital is getting rich, we may expect higher profits from businesses, in fact, the growth of trade is more feasible when human capital could be integrated with ideas and technology. The foreign trade through innovation, creativity and innovation, technology transfer, international labor can be used for technological progress and to achieve higher rates of economic growth.

The expansion of international trade, business administration and economics, economic management improved technology is to discover new and better ways to encourage production. Therefore, the opportunities overlooked in the past could become the main source of economic growth (Miller et al., 2000). There are many businesses with exposure to competition and the profit motive and the benefits of international trade, trying to use new techniques and best practices to use in developing their products. Employing new and advanced technology in production will result in formation of 
numerous inventions and innovations, as well as manufacturers who are trying to offer products with the lowest cost possible (Soderbom \& Teal, 2003).

Technology transfer through foreign trade and labor skills have recently been amplified but the capability to take advantage of technology transfer business in an economy depends on many factors, such as social inclusion and social capacity of an economy determined by human capital variables. Gender has recently become an important issue for business development but there are some challenges on implementing women in many businesses since the may gradually lose some of their rights and privileges when they are heavily involved in workforce. Nevertheless, there are many opportunities around the world specially in educational environment where women play more essential role. Today, women' employment is considered as one of the indicators of developed societies. Widespread uptake of women in the labor market, particularly in the advanced industrial countries, has been realized. Even a country like Finland, non-agricultural working population has reached 41 percent of employed women in the general population. Anderson (2005) argued that trade leaves intact the countries in which men and women have various levels of skills, the wage gap between women and men through the gap of skilled and unskilled labor would increase (1971). Becker (1971) state stated that with increased competition in product markets and economic leave tact wage gap between men and women decrease.

Development should enable all individuals to increase their capabilities to the greatest possible extent. The increase and improvement on women's participation on the one hand, creation an incentive for other women to make the effort and increase their efforts and on the other hand, has positive impact on a society.

In summary, the overall picture that emerged from the literature supports positive and significant relationship of labor, physical capital, and economic growth of leaves intact of the whole country. In most studies, the focus is on human capital and not gender. The goal is to study the impact of separated human capital and to assess gender-based economic growth in Iran and selected countries.

\section{The proposed model}

Level of knowledge and expertise in the field of labor promotes better use of existing capacity in the country. Scientific capacity of the labor force improves the conditions of using existing resources and promotes the feasibility of using new materials and methods. Since there is an increasing trend on human capital in most countries, we may expect an increase on innovation, quality and performance leading to a more flexible work force in the advancement of technology. We may also see an increase on using imported technology, which leads to a more flexible work force in the advancement of technology and the an increase on the use of imported technology, the production and national income.

Accordingly, women's human capital directly increases national production, and by increasing human capital, we may expect an increase on sustainable economic growth. Thus, in the observed growth and productivity functions, it is possible that human capital is investigated based on gender. There are several models to explain economic growth of a country's per capita growth over time and comparisons among countries is also provided by economists. One of the first models in this context is that the overall pattern Solo $Y=F(K t, A t L t)$ where the production function $Y, K$ physical capital, $L$ labor, and $A$ represents technical knowledge or performance of the work force. Other patterns to explain variations in per capita income over time or between countries. This pattern is also rooted in the neoclassical growth model of Solow (1956) and a family of endogenous growth models, the Cobb-Douglas production function, so that a general form is defined as follows,

$Y=F(K t, H t)$, 
where $t$ represents time, $F$ denotes production function, $K$ and $H$ denote capital and human resources and is denoted by the following,

$H t=A t \times L t$.

It is assumed that every person-working hours per year growth rate, $n$ can be written as follows:

$\dot{L}_{t}=n \times L_{t}$.

The high point of a variable indicates the time derivative. Output per unit of capital and human capital are expressed as follows,

$\dot{Y}=Y_{t} / A_{t}$,

$\dot{K}=K_{t} / A_{t}$.

In addition, the output and the capital per person-time are stated as follows,

$y_{t}=Y_{t} / L_{t}$,

$k_{t}=K_{t} / L_{t}$.

The Cobb-Douglas function can be specified as follows,

$Y_{i t}=A_{i t} K_{i t}^{\alpha} L_{i t}^{\beta}$,

where $A$ represents the level of efficiency, $t$ time and $i$ is the mentioned country.

Most of the patterns are discussed in the context of an open economy, particularly for developing countries because of steady growth, "development productivity" mentioned productivity through the development of international trade, education, research and development and improving human capital fails to flow, so that the agent could tend to reduce the marginal returns of capital, to compensate. In these models, improving productivity as the "engine of growth" has been considered in many of these, international trade and improving productivity through technological progress and economic growth engine introduced. In this model, the functional efficiency of foreign trade and human capital is considered as follows,

$\ln A_{i t}=c+\gamma_{1} \cdot \ln T_{i t}+\gamma_{2} \cdot \ln H_{i t}+\varepsilon_{i t}$.

In this equation, the vector of trade variables, indicators of human capital, and disturbing sentence: In this equation, $T$ is the vector of trade variables, $H$ is the indicators of human capital, and $\varepsilon_{i t}$ is the disturbing sentence: $t$, $i$ show time and country, respectively. Using Eq. (2) and Eq. (9), we have,

$\ln \mathrm{Y}_{\mathrm{it}}=\mathrm{c}+\gamma_{1} \cdot \ln \mathrm{T}_{\mathrm{it}}+\gamma_{2} \cdot \ln \mathrm{H}_{\mathrm{it}}+\alpha \cdot \ln \mathrm{K}_{\mathrm{it}}+\beta \cdot \ln \mathrm{L}_{\mathrm{it}}+\varepsilon_{\mathrm{it}}$.

Human capital and labor are both human capital and human capital of women and men into the labor force of women and men in the labor force.

$\ln Y_{i t}=c+\gamma_{1} \cdot \ln T_{i t}+\gamma_{2} \cdot \ln H_{m i t}+\gamma_{3} \cdot \ln H_{f i t}+\alpha \cdot \ln K_{i t}+\beta \cdot \ln L_{m i t}+\beta \cdot \ln L_{f i t}+\varepsilon_{i t}$,

where $m$ and $f$ refer to gender differences, $m$ for male and $f$ for female. Fig. 1 and Fig. (2) show the changes and growth changes in the human capital of women, the importance of human capital in economic growth is also indicated for women. On the other hand, foreign trade, major channel for the transfer of thoughts, ideas, knowledge and technology has advanced. Admission, and social adaptation of these technologies strongly depend on the stock of human capital in the recipient country. The labor for the use and optimization of production technologies and adapt them to local 
conditions, we have the expertise and skills. In this model, the relationship between human capital and foreign trade as a combination of multiplicative $\left(\ln T_{i t} \ln H_{i t}\right.$ ) variable is added to the model as follows,

$$
\begin{aligned}
\ln Y_{i t}= & c+\gamma_{1} \cdot \ln T_{i t}+\gamma_{2} \cdot \ln H_{m i t}+\gamma_{3} \cdot \ln H_{f i t}+\lambda_{1} \cdot\left(\ln T_{i t} \ln H_{m i t}\right)+\lambda_{2} \cdot\left(\ln T_{i t} \ln H_{f i t}\right) \\
& +\alpha \cdot \ln K_{i t}+\beta_{1} \ln L_{m i t}+\beta_{2} \ln L_{f i t}+\varepsilon_{i t},
\end{aligned}
$$

where the logarithm of men is an indicator of human capital education expenditures, education expenditures logarithm of women is an indicator of human capital, physical capital logarithm of the labor force working men and women.

In this study, in order to show the relationship between trade and economic growth in OECD and selected countries of economic openness variable is used as an indicator of foreign trade. Based on the data of the selected OECD countries for the years 1974-2008 and 9 sites and resources, the World Bank and Penn World Table (CD-ROM 2008) is obtained.

\section{4 .Experimental results}

The model for Iran and 9 selected OECD countries during the period, using data from the World Bank and Stata software has been tested. Levels of statistical significance of the estimated probability of accepting the null values are specified. Houseman also chosen test method of random effects (RE) and fixed effects (FE) makes it possible. In addition, the Wald statistic (W) ration Lagrange (LM), respectively, indicating significant regression, random effects results validate the estimated model is compared to other methods. Thus, Table 1 shows the results of estimating Eq. (12) using panel data methods based on random effects (the test Houseman, $\mathrm{H}$ ). The results reported in Table 9 for selected countries of OECD.

The results of Table 1 show that the growth of human capital between men and women is quite positive and there is a significant impact on economic growth in OECD countries. In fact, the cost of education is an investment in human resources, the skills and abilities of people. In these countries, the coefficient of the human capital of women (65.41) is greater than the coefficient of human capital for men (96.12) and it further illustrates the importance of women as human capital in developing countries. The combined effect of business for men and women for human capital on economic growth was statistically significant. In fact, the acquisition of foreign technology and international advanced technologies through technology transfer and learning from one hand into the other are complementary and interdependent.

Table 1

The results of estimating equation (12) for OECD countries using the random effects

\begin{tabular}{lccc}
\hline \multicolumn{1}{c}{ Variable (log) } & Traction coefficient random effects & The statistic Z & Pr>|Z| \\
\hline Cons & -70.33 & -5.75 & 0.000 \\
$\ln K$ & 0.02 & 3.20 & 0.001 \\
$\ln L F$ & 2.87 & 4.16 & 0.000 \\
$\ln L M$ & 8.99 & 3.96 & 0.000 \\
$\ln H F$ & 41.65 & 8.43 & 0.000 \\
$\ln H M$ & 12.96 & 4.61 & 0.004 \\
$\ln T r$ & 16.37 & 8.78 & 0.000 \\
$\ln T r \ln H F$ & 11.91 & 9.22 & 0.000 \\
$\ln T r \ln H M$ & 0.62 & 4.62 & 0.000 \\
\hline
\end{tabular}

Using time series data, Eq. (12) can be estimated. Typically, because of the level of macroeconomic time series variables are non-stationary and we may need to take a difference on data to convert them into stationary. In fact, stability of a time series can be examined using unit root test. The results of the unit root test variables used in the model to calculate the DF statistic in Table 2 is presented. Results in Table 2 show that the variables are not reliable. 
Table 2

Unit Root Tests for Models

\begin{tabular}{lccc}
\hline (log) statistics & Computational statistics & critical significance & Significance level \\
\hline Ln $G D P$ & -1.74 & -2.98 & 0.05 \\
Ln $K$ & -2.44 & -2.98 & 0.05 \\
Ln $L F$ & -0.68 & -3 & 0.007 \\
Ln $L M$ & 0.07 & -3 & 0.003 \\
Ln $H F$ & -0.97 & -2.98 & 0.000 \\
Ln $H M$ & -2.15 & -2.98 & 0.000 \\
Ln $T r$ & -1.77 & -2.98 & 0.05 \\
Ln $T r$ Ln HF & -1.33 & -2.98 & 0.000 \\
Ln $T r$ Ln $H M$ & -2.28 & -2.98 & 0.69 \\
\hline
\end{tabular}

The results of Table 3 show that static variables are making a difference and are the integration of the first order. Therefore, the statistics are calculated by the DF represents the significance level of 5\% or less down on the table and stagnation that they are making a difference.

Table 3

Unit root tests for the first difference of

\begin{tabular}{lccc}
\hline (log) statistics & Computational statistics & critical significance & Significance level \\
\hline Ln GDP & -4.55 & -2.99 & 0.05 \\
Ln $K$ & -6.52 & -2.98 & 0.05 \\
Ln $L F$ & -3.84 & -3 & 0.007 \\
Ln $L M$ & -3 & -2.92 & 0.003 \\
Ln $H F$ & -6.64 & -2.99 & 0.000 \\
Ln $H M$ & -3.15 & -2.99 & 0.000 \\
Ln $T r$ & -3.07 & -2.99 & 0.000 \\
Ln $T r$ Ln HF & -6.24 & -2.99 & 0.000 \\
Ln $T r$ Ln $H M$ & -8.07 & -2.99 & 0.69 \\
\hline
\end{tabular}

Because the model variables are integrated of degree one static regression test to check for parasites Granger (1982) based on the unit root test on the residual is used. To investigate the stability of the regression results Engel-Granger (1987) test the long-term equilibrium relationship of the collective offered. Long-term relationship in the sense that the first-order variables are collective. So check the collective variables from OLS Regression Testing is frozen wastes. Method of Dickey- Fuller (DF) sentences static hysteresis $\left(e_{t}\right)$ does the following tests:

$$
\Delta e_{t}=e_{t-1}+V_{t} .
$$

The estimation results of unit root test on the residual terms of the estimated regression Eq. (12) in Table 4 are summarized

Table 4

Unit root test for the residuals of

\begin{tabular}{ccc}
\hline$(\log )$ statistics & Computational statistics & Significance level \\
\hline-5.45 & -2.99 & 0.05 \\
\hline
\end{tabular}

The results of Table 5 show that the human capital of men and women both have positive and significant impact on economic growth in Iran. Multiplicative variable trade and human capital of women, a significant positive effect on economic growth and development have indicated that the impact of trade on economic growth influenced the growth of women's human capital, i.e., more trade wider education workforce can be more at stake. Foreign trade with countries that are able to achieve intermediate products and capital equipment, copying, foreign technology and advanced manufacturing techniques and methods, but the use of this technology are native to it and adapt it to local conditions of production, skilled professional manpower needs. The impact of foreign trade on 
economic growth in these countries has been influenced by the growth of human capital. Therefore, investment on human resources to improve the skills, knowledge and technical ability can strive to improvement of production and development of a deeper approach to business. However, the growth of labor and physical capital growth has had a positive and highly significant effect on economic growth. In other word, a 1\% increase in physical capital growth increases $52.6 \%$ in economic growth.

Table 5

The results of estimating Eq. (13) for Iran

\begin{tabular}{lccc}
\hline Variable (logarithmic) & Values of tensile test random effects & The t-statistics & Pr $>|\mathrm{t}|$ \\
\hline Cons & 8.52 & 2.47 & 0.025 \\
Ln $G D P$ & 0.45 & 5.78 & 0.000 \\
Ln $K$ & 0.52 & 3.10 & 0.000 \\
Ln $L F$ & 2.15 & 3.49 & 0.003 \\
Ln $L M$ & 0.00016 & 13.20 & 0.000 \\
Ln $H F$ & $11 \mathrm{e}^{-1.68}$ & 4.88 & 0.000 \\
Ln $H M$ & 0.35 & 10.31 & 0.000 \\
Ln $T r$ & 0.35 & 10.62 & 0.000 \\
Ln $T r$ Ln $H F$ & $0.01 \quad 0.40$ & 0.69 \\
\hline \multicolumn{2}{c}{$R^{2}=0.96$} \\
\hline
\end{tabular}

\section{Conclusion}

This paper has investigated the effects of human capital on economic growth of men and women in selected OECD countries over the period 1974-2008. Results showed that expansion, commercial development, achieved growth, economic development and human capital in selected countries could be at stake. In other words, these countries can enjoy the benefits of international trade, the stock of human capital and the knowledge and expertise of its personnel have been high. Especially in the development of human capital is more important for women because women make up a large part of the educated people.The main message of this study is the role of women in the economic, efficient and effective stresses. The third factor in manpower, the role of women in the economic model that has scientific support in the empirical literature is confirmed.

\section{References}

Abramovitz, M. (1986). Catching up, forging ahead, and falling behind. Journal of Economic history, 46(2), 385-406.

Anderson, E. (2005). Openness and inequality in developing countries: A review of theory and recent evidence. World Development, 33(7), 1045-1063.

Becker, G. S. (2010). The economics of discrimination. University of Chicago press.

Becker, G. S. (2009). Human capital: A theoretical and empirical analysis, with special reference to education. University of Chicago Press.

Engle, R. F., \& Granger, C. W. (1987). Co-integration and error correction: representation, estimation, and testing. Econometrica: journal of the Econometric Society, 251-276.

Isaksson, A. (2002). The Importance of Human Capital for the Trade Growth Link: Anders Isaksson. Statistics and Information Networks Branch of UNIDO.

Islam, N. (1995). Growth empirics: a panel data approach. The Quarterly Journal of Economics, 110(4), 1127-1170.

Lau, L. J., Jamison, D. T., \& Louat, F. F. (1991). Education and productivity in developing countries: An aggregate production function approach (Vol. 612). World Bank Publications.

Larson, P. D., \& Morris, M. (2008). S-ex and salary: A survey of purchasing and supply professionals. Journal of Purchasing and Supply Management, 14(2), 112-124.

Di Liberto, A. (2008). Education and Italian regional development. Economics of Education Review, 27(1), 94-107. 
1732

Lucas Jr, R. E. (1988). On the mechanics of economic development. Journal of monetary economics, 22(1), 3-42.

Miller, S. M., \& Upadhyay, M. P. (2000). The effects of openness, trade orientation, and human capital on total factor productivity. Journal of development economics, 63(2), 399-423.

Pritchett, L. (2001). Where has all the education gone?. The World Bank Economic Review, 15(3), 367-391.

Psacharopoulos, G. (1972). Measuring the marginal contribution of education to economic growth. Economic Development and Cultural Change, 20(4), 641-658.

Romer, P. (1991). Endogenous technological change (No. w3210). National Bureau of Economic Research.

Romer, P. M. (1986). Increasing returns and long-run growth. The Journal of Political Economy, 1002-1037.

Smith, A., Stewart, D., \& Garnier, M. (1825). Wealth of nations (Vol. 1, pp. 138-140). BiblioBytes.

Soderbom, M., \& Teal, F. (2003). Trade and human capital as determinant of growth. Department of economics, University of Oxford. 